Pure \& Appl. Chem., Vo1. 51, pp. 261-270.

Pergamon Press Ltd. 1979. Printed in Great Britain.

\title{
PHOTOCHEMISTRY OF SOME THREE-MEMBERED HETEROCYCLES
}

\author{
A.M. Trozzolo, "T.M. Leslie, A.S. Sarpotdar, R.D. Sma11 and G.J. Ferraudi \\ Department of Chemistry and Radiation Laboratory (1), University of Notre Dame, \\ Notre Dame, IN 46556 USA \\ and \\ T. DoMinh (2) and R.L. Hartless \\ Be11 Laboratories, Murray Hill, NJ 07974 USA
}

Abstract - The solid-state photolysis of oxiranes and aziridines produces highly colored ylide intermediates. The stability of these intermediates is dependent on a combination of electronic and steric factors as well as the solid-state constraints of the environment.
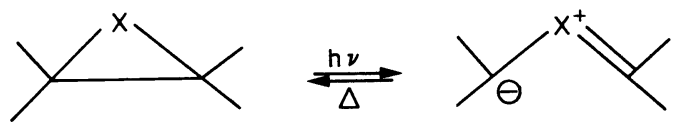

$$
\begin{aligned}
X & =-O- \\
& =-N-R
\end{aligned}
$$

\begin{abstract}
Flash photolysis studies indicate that two different ylides can be produced in solution at room temperature. These intermediates appear to be identical to those formed consecutively in the solid state or lowtemperature glasses. By the use of certain gas-solid reactions, it is possible to control the lifetime of the intermediate so that it is destroyed immediately or continues to exist almost indefinitely.
\end{abstract}

\section{INTRODUCTION}

The room temperature photolyses of aryloxiranes have been shown by Griffin and co-workers to involve a two-bond cleavage producing aryl carbenes and carbonyl compounds $(3,4)$. On the other hand, the thermal transformations of aryl aziridines were interpreted by Heine (5) and Huisgen (6) as one-bond cleavages producing azomethine ylide intermediates which could be trapped with suitable dipolarophiles.

Our previous interest in low temperature and solid-state photochemical techniques (7-9) suggested the possibility of obtaining direct physical evidence for the above intermediates on photoreactions carried out at $77^{\circ} \mathrm{K}$. The results of several of these studies already have appeared (10-13) and this report will describe additional recent work with special emphasis on the relation of the low-temperature studies to the unusual room-temperature solid-state photochemistry which is exhibited by many of the compounds.

\section{LOW TEMPERATURE PHOTOCHEMISTRY OF ARYL OXIRANES}

The room temperature photochemistry of aryloxiranes has been studied extensively by Griffin and co-workers $(3,4)$. The reactions involve a cycloelimination on photolysis in solution to give aryl carbenes and carbonyl compounds.
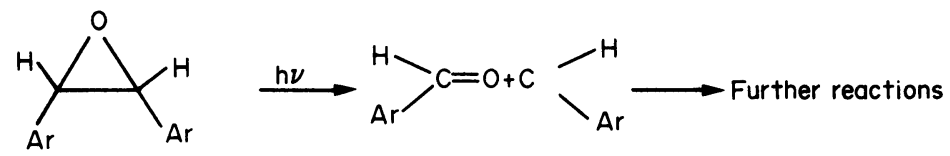
The aryl carbenes were trapped by a variety of reagents, notably by reaction with an alcohol to give the appropriate aryl methyl alkyl ether or reaction with an olefin to give the appropriate cyclopropane. In addition, the insertion selectivity of phenylcarbene generated from trans-stilbene oxide into the aliphatic $1^{\circ}$ and $2^{\circ} \mathrm{C}-\mathrm{H}$ bonds of $\mathrm{n}$-pentane was found to be comparable with tht using the more familiar phenylcarbene precursor, phenyldiazomethane (14).

The photolysis of aryl oxiranes at $77^{\circ} \mathrm{K}$ in rigid glasses also produces aryl carbenes and carbonyl compounds. The products have been identified by their luminescence properties $(10,15)$ and epr spectra $(10)$. In addition, highly colored intermediates are formed, which, while stable at low temperatures, are bleached by warming to $25^{\circ} \mathrm{C}$. Evidence has been presented $(11,15 \mathrm{~b}, 16)$ that the colored intermediates are very probably carbonyl ylides, 2 , and that the opening and recyclization occurs via a concerted disrotatory process with conservation of orbital symmetry.

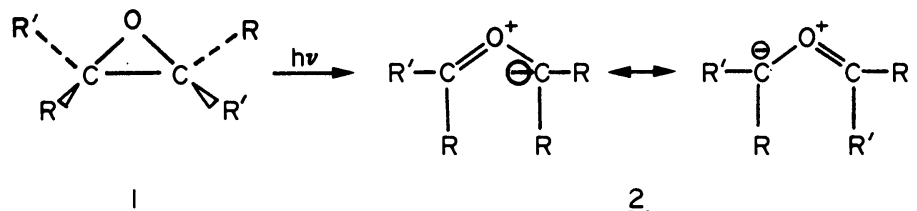

Typical examples of these transformations are the photolyses of cis and trans-stilbene oxide.

Irradiation of trans-stilbene oxide, 3 in ethanol glass at $77^{\circ}$ produced an orange compound along with small amounts of benzaldehyde, phenylmethylene and desoxybenzoin. The absorption spectrum of the colored species had a maximum at $270 \mathrm{~nm}$ and a band in the visible $\left(\lambda_{\max }=490\right.$ $\mathrm{nm}, \varepsilon \geq 10^{4}$ ). Irradiation of the cis-isomer, 5 , gave similar products, but the colored intermediate was a deep red compound $\left(\lambda_{\max }=510 \mathrm{~nm}\right)$. Near $140^{\circ} \mathrm{K}$, both colorations disappeared, that from the trans-sample being more rapid than the $\mathrm{cis}$, and benzaldehyde and phenylmethylene produced. The amount of fragmentation products formed by this photolysiswarmup procedure was estimated to be 20-50 times more than originally produced by photolysis. The rate of fading on warming was noticeably greater if norbornadiene or dimethyl acetylenedicarboxylate were present. Significantly both reagents are efficient dipolarophiles. Irradiation in the visible (450-w Hanovia medium pressure arc, pyrex filter) caused rapid fading and regenerating the original oxirane with little fragmentation. In no case could cis- trans- isomerization be detected in the recovered oxirane which had undergone repeated double photolysis cycles or photolysis-warmup resulting in $15 \%$ conversion to products. Three possible carbonyl ylides may be derived from the isomeric stilbene oxides.<smiles>c1ccc(C2OC2c2ccccc2)cc1</smiles><smiles>c1ccc(C2OC2c2ccccc2)cc1</smiles>

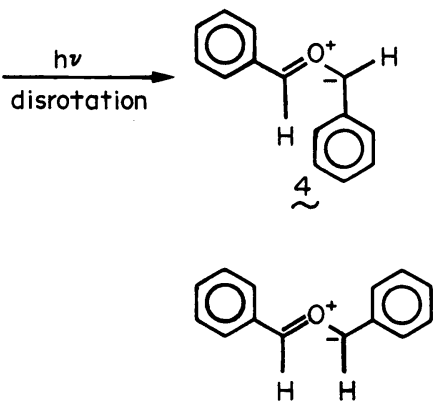

$\underline{20}$

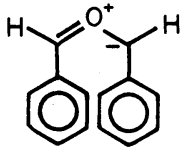

6b

It is evident for stereoelectronic reasons that the order of stability is $6 \mathrm{a}>4 .>\mathrm{b}$. Since $6 \mathrm{~b}$ can only be formed in conjunction with 6 a regardless of the mode of rotation, its formation is highly improbable. The validity of this view is supported by the results of Huisgen and co-workers on the isoelectronic aziridine-azomethine ylide system (17). Only the two ylides having structure corresponding to 4 and 6 a could be found as cycloadducts and the equilibrium at $100^{\circ}$ between the two forms was substantially in favor of the cis-exo 
isomer. From the relative stability and absorption spectrum, it is possible to assign the cis-exo ylide 6 a to the more stable red-shifted intermediate from cis-stilbene oxide, and the trans-ylide 4 to the one from trans-stilbene oxide. Consequently, the electro-cyclic reaction must involve a disrotatory course, and in the case of cis-stilbene oxide, an "outward" disrotation. This conclusion is confirmed by the photochromic behavior of bicyclic oxiranes whose special geometry permits only an outward disrotatory course. Thus irradiation of 1,2-diphenylcyclopentene oxide $Z$ or the six-membered homolog, yielded a bright red intermediate which, upon irradiation further with visible light, quantitatively reverted to oxirane. Only by warming were other products formed, among which was a compound tentatively identified as the open-chained unsaturated ketone $\&$. The facile photochromism is attributed to the fact that ylides from these ring systems are rigidly maintained in the proper geometry for cyclization.

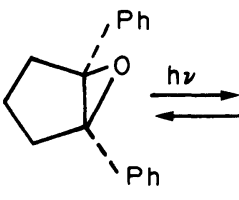

7

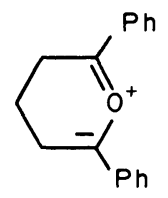

Ph

(1)

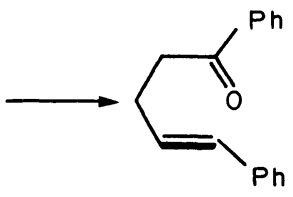

8

Furthermore, the low temperature photolysis of tetraphenyloxetanone, 9 , formed a blue compound identical with the intermediate from tetraphenyloxirane confirming a $\mathrm{C}-\mathrm{C}$ cleavage in the ring opening (11).

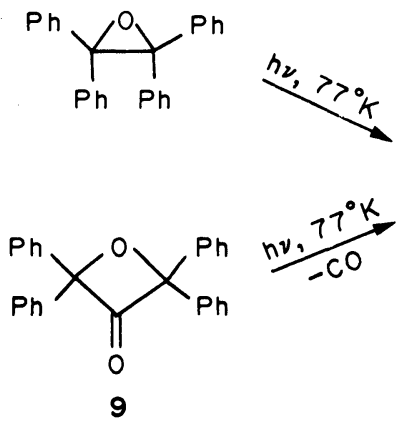<smiles>O=C([O+]=[Po+]c1ccccc1)c1ccccc1</smiles>

Direct evidence for the formation of a carbonyl ylide from an oxirane was obtained by Arnold and Karnischky (16) who found that both the photolysis and pyrolysis $\left(100^{\circ} \mathrm{C}\right)$ of 5-axa-bicyclo (2.1.0)-pentane, 10, gave purple intermediates whose visible absorption spectra were essentially indistinguishable. The carbonyl ylide structure 11 was assigned to the purple intermediate.

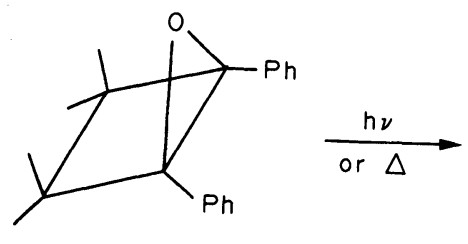

10

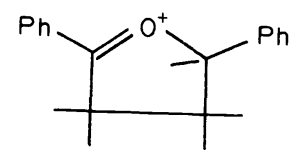




\section{PHOTOCHROMISM IN MONO-CYCLIC AZIRIDINES}

The photo-induced reversible color changes in certain aryl aziridines have been recognized for some time. Cromwell and co-workers reported that exposure of 1-benzy1- and 1-cyclohexy12-pheny1-3-benzoy1-aziridine to diffuse daylight produced the rapid development of a deep pink color, and that the coloration faded on standing in the dark (18). Heine and coworkers (19) synthesized a series of interesting bicyclic aziridines which were noted to be strongly photochromic. Also, Padwa and Hamilton (20) studied the photochromic behavior of several monocyclic aziridines.

The following discussion will present evidence that the colored species from both the monoand bicyclic aziridines are best described in terms of an azomethine ylide structure $(12,13)$. Further, the stereoelectronic influences on the stability and color of the intermediates will be described, and in addition, the contrast in mechanism between the ring opening of mono-cyclic and bicyclic aziridines will be interpreted as indicating the strong possibility of a photo-induced thermal reaction for the bicyclic aziridines.

It has been found that the presence of either a phenyl- or benzoyl substituent on both ring carbons of the aziridine constitutes the structural requirement for photochromism. All aziridines of this type will display a color upon photolysis at $77^{\circ} \mathrm{K}$ either in the solid state or in glassy solution (Table I). On warming slowly, the colors fade and the aziridine is reformed. As can be seen in Table $I$, the color of the intermediate is dependent on the substituents and the stereochemistry of the aziridine ring. Similar observations had been made on the previously studied aryl oxirane-carbonyl ylide systems $(11,21)$.

TABLE I. Stereochemical effects in low temperature photolysis of monocyclic aziridines

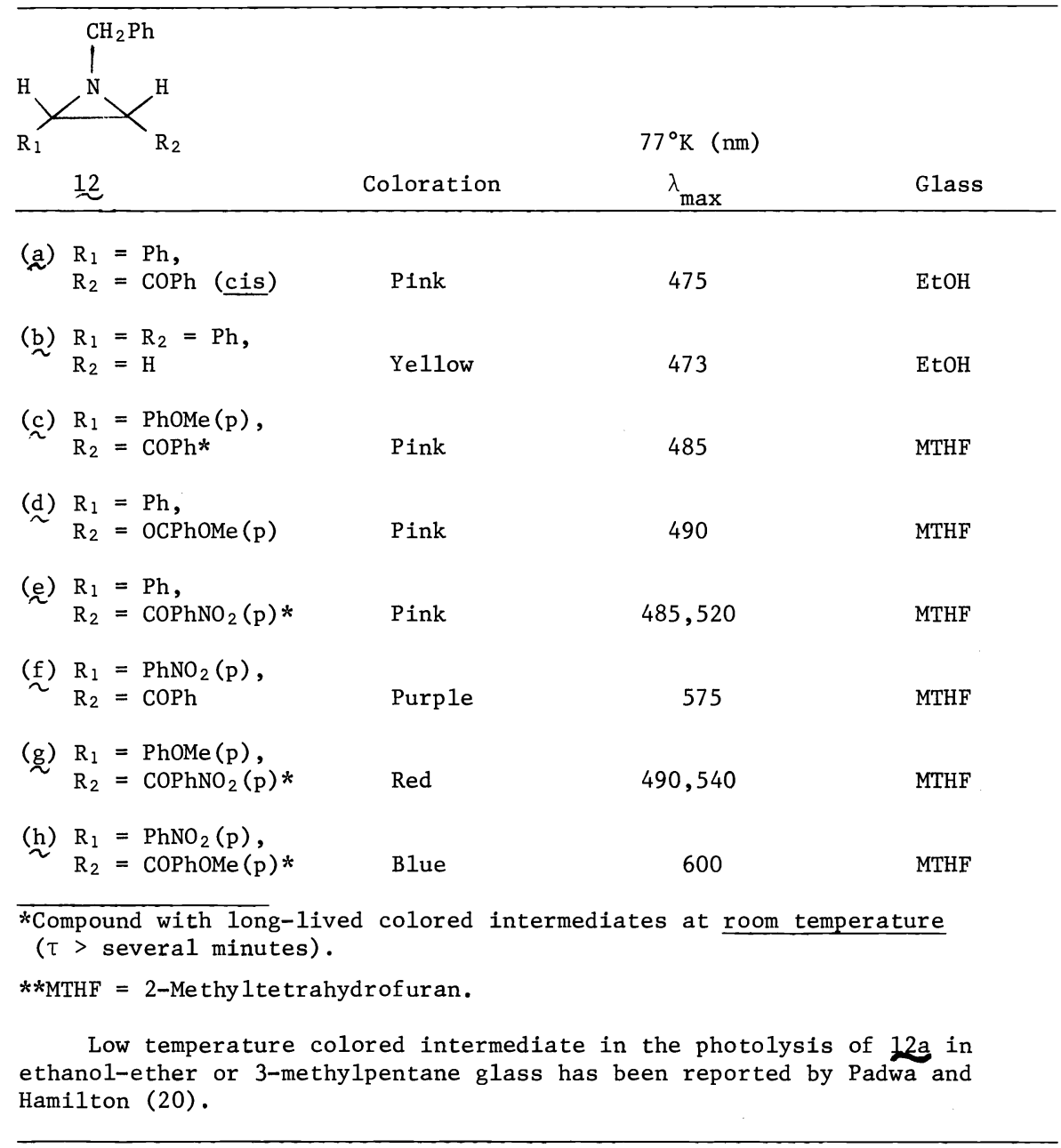


One of the consequences of the azomethine ylide hypothesis is that it should be possible to increase the stability of the dipolar intermediate with substituents known to have substantial electronic effects. Thus, substituents which aid charge separation might be expected to stabilize the ylide to the extent it would survive at higher temperatures. When groups such as nitro- and methoxy- were introduced into the para- positions of the aromatic substituents<smiles>[Y][PH2]C(=O)C1([2H])CN1[R]</smiles>

12

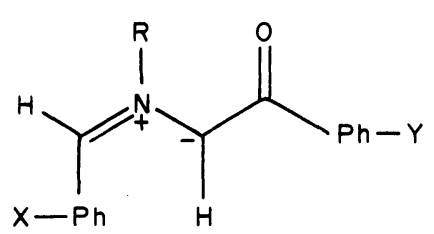

13

of the aziridines, it was found that, indeed, the absorption of the colored intermediate was red-shifted and its stability was improved markedly (Table I). The methoxy group apparently has little or no effect on the absorption spectrum of the colored intermediate, but provided considerable stabilization when it was incorporated in the phenyl substituent (12a vs. $12 \mathrm{c}, 12 \mathrm{~d})$. The nitro group, on the other hand, exerts a pronounced effect on the absorption spectrum of the intermediate when it is present on either substituent of the aziridine ring. However, its stabilizing effect is more evident when it is on the benzoyl group (12e, 12f). The combined effect of these two groups is quite spectacular and leads to a system such as $12 \mathrm{~h}$ which is photochromic at room temperature. A blue coloration rapidly developed when crystals of this material were irradiated with light of wavelength below $400 \mathrm{~nm}$. The colored intermediate can be reverted to the parent aziridine by a second irradiation into the visible band, or by remaining in the dark at $25^{\circ}$ for 15 minutes. The blue crystals are completely dichroic (blue $\longleftrightarrow$ transparent) when viewed with polarized light. When the two groups are interchanged as in $12 \mathrm{~g}$, irradiation gives rise to a red intermediate which is remarkably stable at moderate temperatures (life time of the colored intermediate at $25^{\circ}$ is greater than 24 hours). Also, the coloration could be achieved by warming as well as by irradiation, and, in addition, the photothermochromic behavior was observable even in solution. Addition of dimethylacetylenedicarboxylate (DMADC) instantly discharged the color. Further heating ( $110^{\circ}$ for 30 minutes) did not produce the color but gave a $64 \%$ yield of pyrroline 15 (mp $\left.126-8^{\circ}\right)$. The identification of this cycloadduct was based on uv, ir and nmr spectral data.

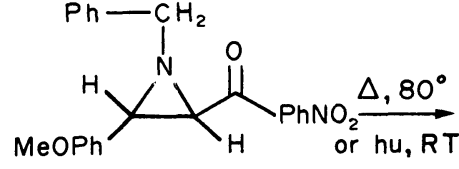

129<smiles>CO[P+](C)([O-])C(=O)C=[N+](Cc1ccccc1)C(C)=[P+](C)C</smiles>

14<smiles>COC(=O)C1=C(C(=O)O[Na])[C@H](C(=O)O[Na])[C@H](c2ccccc2)N1Cc1ccccc1</smiles>

15

Photolysis of $12 \mathrm{e}$ in 2-methyltetrahydrofuran solution at $77^{\circ} \mathrm{K}$ gave rise to a pink color which had a substantially different absorption from its room temperature absorption ( $\lambda_{\max }$ 490 and $540 \mathrm{~nm}$, vs. $486 \mathrm{~nm}$ at room temperature), but the differencedisappeared on warming. If the ring opening of the aziridine can be assumed to occur in the excited state, a disrotation, as predicted by the Woodward-Hoffmann rules (22) would result in a pair of trans ylides 16 which could isomerize to the more stable cis-form, 17 . However, the stereochemistry of the cycloadduct 15 is not known. 


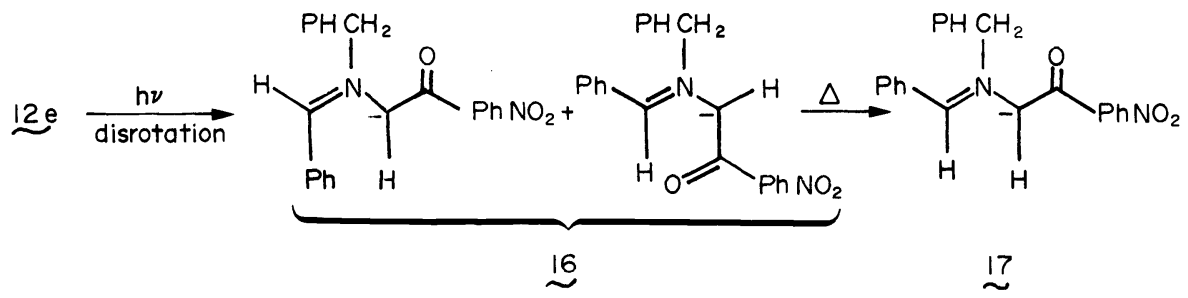

\section{PHOTOCHROMISM IN BICYCLIC AZIRIDINES}

A contrasting behavior is shown by the series of bicyclic aziridines which were just described by Heine and co-workers (19). Typical of the compounds which were investigated (Table II) is $18 \mathrm{a}$, which is a colorless crystalline material, mp 182-190,$\lambda \mathrm{EtOH}^{\circ} 250 \mathrm{~nm}$ $\left(\varepsilon=3.0 \times 10^{4}\right), 283 \mathrm{~nm}\left(\varepsilon=2.3 \times 10^{4}\right)$. Crystals of $18 \mathrm{a}$ or its glassy solutions at $77^{\circ} \mathrm{K}$ upon exposure to light $(\lambda<450 \mathrm{~nm})$ rapidly developed an intense blue color $\left(\lambda \max 77^{\circ} 605 \mathrm{~nm}\right.$, $\left.\varepsilon \simeq 5 \times 10^{4}\right)$. The color could be erased by irradiation in the visible $(\lambda>550 \mathrm{~nm})$ or by heat. At room temperature and in the dark the color faded in 12 hours ( 3 min. at $110^{\circ}$ ) with first order kinetics.

In solution, the lifetime of the colored intermediates was much shorter (several minutes at room temperature) and their formation was not entirely reversible due to a competing enedilmine formation $(12,23)$. In an earlier report (12), we had shown that the enedilmine was formed via transient colored intermediates which were 1,3-dipoles (azomethine ylides). We since have found tht these same colored intermediates were obtained when the aziridines were irradiated in the crystalline state and subsequently dissolved in solvents (13). Their absorption spectra in $\mathrm{KBr}$, except for a small red shift, closely parallel those taken in rigid glasses at $77^{\circ} \mathrm{K}$, and undoubtedly are due to the same species. The red shift in $\mathrm{KBr}$ spectra at $25^{\circ}$ can be attributed to a matrix and temperature effect.

TABLE II. Photochromic bicyclic aziridines.

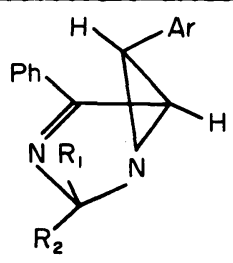

Colored Intermediates

$\stackrel{18}{\sim} \quad \lambda_{\max }^{77^{\circ} \mathrm{K}}(\mathrm{nm})$, glass $\lambda_{\max }^{\mathrm{KBr}} \cdot 25^{\circ}(\mathrm{nm}) \quad$ Color

(a) $\mathrm{R}_{1}=\mathrm{R}_{2}=\mathrm{Me}$,

$\mathrm{Ar}=\mathrm{PhNO}_{2}(\mathrm{p})^{\mathrm{a}}$

MTHF

625,580 (Sh.) B1ue

(b) $\mathrm{R}_{1}=\mathrm{Ar}=\mathrm{Ph}$,

$\mathrm{R}_{2}=\mathrm{H}$ (exo-cis $^{\mathrm{b}}$

512,485 (Sh.) EtOH

526,495 (Sh.)

Pink

(c) $\mathrm{R}_{1}=\mathrm{Ph}, \mathrm{R}_{2}=\mathrm{H}$, $\mathrm{Ar}=\mathrm{PhNO}_{2}(\mathrm{p})\left(\right.$ exo-cis) ${ }^{\mathrm{c}} 610,570$ (Sh.) MeTHF

$645,600($ Sh. $) \quad$ Green

Heine et al. (19).

$\mathrm{b}_{\text {Padwa }}$ et a1. (23) isolated $18 \mathrm{~b}$ when preparing the exo-trans isomer according to Heine procedure.

$\mathrm{C}_{\mathrm{Mp}} \cdot 166-7^{\circ}$; we prepared $18 \mathrm{c}$ and its exo-trans isomer (mp. 175-6 ${ }^{\circ}$ ) using Heine-Padwa methods. 
In agreement with the proposed 1,3-dipolar structure and in behavior similar to that of the monocyclic aziridines, the stability of the colored intermediates is strongly influenced by both electronic and steric changes in the structure of the aziridines. Thus, removal of the nitro group, or shifting it to a meta position markedly reduced the photochromic sensitivity of the aziridines and blue-shifted the absorption spectrum of the colored species (Table II). The second fused ring, especially with 2-substituents, appears to stabilize the ylide relative to the aziridine. When this added ring strain is eliminated as in $12 \mathrm{f}$ (Table $\mathrm{I}$ ), irradiation produced a purple coloration which was stable only at $77 \mathrm{PK}\left(\lambda \lambda_{\max }^{\mathrm{tOOH}}, 77^{\circ} \mathrm{K} 580 \mathrm{~nm}\right)$ and faded instantly on warming to room temperature. Compound 19 (24) with an unsubstituted fused 6-ring, exhibited intermediate sensitivity $\left(\lambda \mathrm{max}, 77^{\circ} \mathrm{K} 605 \mathrm{~nm}\right.$, lifetime of $15 \mathrm{~min}$. at $25^{\circ} \mathrm{C}$, blue color readily erased by visible light).

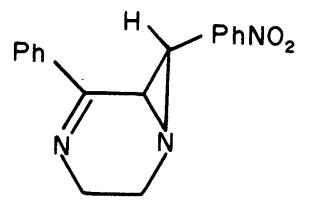

19

Interestingly, irradiated single crystals of the aziridines were found to be highly dichroic. The blue monoclinic crystals of $18 \mathrm{a}$ absorbed strongly along one axis, but were transparent in the perpendicular direction when observed under a polarizing microscope. The anisotropy presumably reflects a highly stereospecific ring opening of the aziridines. Practical applications of this phenomenon have been discussed (25).

The crystals of the oxalic acid salt of 18a like 18a itself were found to give a reversible photochromic reaction. When a thin coating of this salt on filter paper was exposed to sunlight, a red coloration was produced. In the dark, this red color lasted for more than three weeks at room temperature. The red colored species could be regenerated by a second exposure to uv or sunlight. Like 18a this coloration-erasure cycle could be repeated as many times as desired. The color intensity appeared to be practically constant indicating that the salt is quite resistant towards any decomposition. The much longer lifetime of this red intermediate ( $>3$ weeks) as compared to that of the blue species ( $\simeq 12$ hours) derived from 18a was expected since this fact is consistent with the photoinduced azomethine ylide formation from 18a, while a partial charge neutralization in the ylide produced from the oxalate salt would decelerate the reverse ring closure.

That the red color was in fact due to the protonated azomethine ylide was further supported by a gas-solid reaction. A stream of dry ammonia gas was passed over the red intermediate which instantly became blue colored to give the azomethine ylide of 18 a itself. This blue color was stable only for $¥ 3$ hours though it could be regenerated several times with uv irradiation. This blue colored species gave an absorption spectrum (KBr) which was identical to that of the blue species obtained form 18a.

\section{THE "PHOTOCHROMISM" OF N-3-PYRIDYLSYDNONE}

The photochromic properties of a sydnone were first observed by Tien and Hunsberger $(26,27)$ during an investigation of the usefulness of these compounds in the preparation of heterocyclic hydrazines. They found that when the white crystals of N-3-pyridylsydnone 20 were irradiated, a blue coloration was generated which was thermally bleached. However, little information has been obtained which allows an unambiguous detailing of the structure of the colored intermediate or of the mechanism of the process. Mills, van Roggen, and Wahlig (28) have proposed that the photocoloration process occurs by the production of color centers which are formed at crystal imperfections. We present the results of low-temperature photochemical and spectroscopic studies which suggest that the blue color is the result of a substantially non-reversible two-step process. The first step is considered to be a photo-induced generation of a bicyclic diaziridine 21 via an orbital-symmetry-allowed disrotatory ring closure, and the second step (which produces the color) is a thermal conrotatory ring opening to form the blue intermediate. 


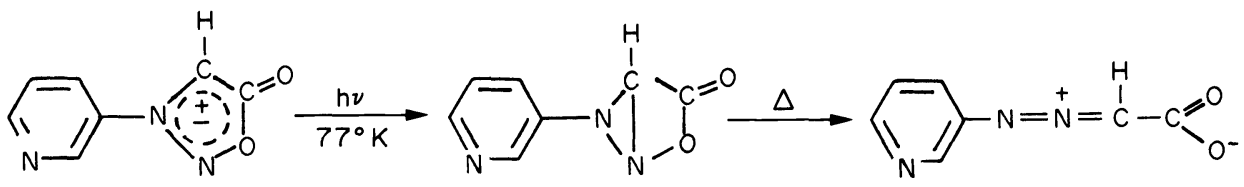

(Colorless)

21
(Blue)

22

Irradiation $\left(\lambda=300 \mathrm{~nm}\right.$ ) of $\mathrm{N}-3$-pyridylsydnone (29) in a $\mathrm{KBr}$ disc at $77^{\circ} \mathrm{K}$ for 2 min. caused a sharp decrease in the UV absorption band at $315 \mathrm{~nm}$ and a slight decrease in the absorption band at $230 \mathrm{~nm}$. Upon prolonged irradiation, the absorptions at $315 \mathrm{~nm}$ and $230 \mathrm{~nm}$ disappeared and were replaced by a new absorption band at $270 \mathrm{~nm}$. Significantly, these UV absorption changes occurred without the appearance of any blue coloration. Subsequent warming of the $\mathrm{KBr}$ disc in the dark led to the development of the blue color $\left(\lambda_{\max }=630 \mathrm{~nm}\right.$, broad) whose intensity was dependent on the irradiation time. However, roomtemperature irradiation produced the blue color immediately with essentially the same UV changes as noted in the low-temperature irradiation.

We interpret these results in terms of a photoinduced-allowed electrocyclic disrotatory ring closure of the sydnone to form a bicyclic diaziridine. The sydnone ring may be represented by several zwitterionic structures (30).<smiles>[R]c1c([O-])on[n+]1[R]</smiles>

The two structures illustrated here constitute an ylide system similar to those which have been assigned to the colored species that are observed in the photolysis of oxiranes and aziridines $(11,13)$. In these cases, photochemical interconversions can occur between the closed ring precursors and the respective azomethine and carbonyl ylides.<smiles></smiles>

23<smiles>O=C(O)C12C(=O)ON(C1c1ccccc1)N2c1ccccc1</smiles><smiles></smiles>

24
Thermal product<smiles>CC(=O)c1nn(-c2ccccc2)c(-c2ccccc2)c1C(C)=O</smiles>

In the low-temperature photolyses of the sydnone, the converison of the sydnone ring 20 to the bicyclic system 21 would be reflected in a decrease in the UV absorption due to the aromatic sydnone ring ( $\mathrm{N}$-alkylated sydnones have absorptions only at $\sim 320 \mathrm{~nm}$ and 230 $\mathrm{nm}$ ) and an increase in the relative absorption which is typical of pyridine. Apparently, the bicyclic species is stable at low temperature, but obviously would be expected to be highly strained. Relief of this strain by an orbital-symmetry-allowed conrotatory thermal reformation of the sydnone is impossible because of stereochemical restraints in the fused bicyclic system. This situation is analogous to the electrocyclic reactions of 
5-oxabicyclic-[2.1.0]-pentane (16) in which the central bond cleavage occurs readily by a photo-induced disrotatory path but with some difficulty via a thermal path (which would be the allowed conrotatory process). The bicyclic oxirane must be heated to $100^{\circ}$ to form the same colored intermediate which can be formed easily by photolysis (16). The conversion of the initial photoproduct 21 to the blue intermediate at low temperature is apparently a thermal process with low activation energy. The relief of the steric strain of 21 and the concomitant production of the blue color can be attributed to the allowed conrotatory cleavage of the external $\mathrm{C}-\mathrm{N}$ bond to yield 22. The extended conjugated system in 22 would account for the longer wavelength absorption. Also, this second step would be unrevealed as a "dark" reaction in the room temperature photocoloration. Metz, Servoss and Welsh (31) were unable to see significant differences in the transmission infrared spectra of irradiated and unirradiated samples of 20. probably because the photolysis is a surface reaction and the transmission spectrum is therefore an insenstive analytical technique. However, we found that even the use of internal reflectance infrared spectroscopy gave essentially the same results that Metz, et. al. (31) obtained earlier, namely, overall broadening and a decrease in intensity of all the peaks. The increased sensitivity of the surface technique was still not sufficient to reveal any deletions or additional IR absorption bands. On the other hand, one might not expect the IR spectrum of 22 to be very different from that of 20 .

Additional evidence for the intermediacy of ylide 22 is found in the absence of color development when 20 is photolyzed in the presence of dimethylacetylenedicarboxylate, a well-known dipolarophile. However, attempts to isolate and identify the products from these trapping experiments so far have been unsuccessful. Also, the above interpretation is consistent with the previously reported solution photochemistry of diphenylsydnone 23 which was carried out by Angadiyavar and George (32). They found that the pyrazoles, 24 and 25 , which were isolated from the thermal and photochemical trapping experiments with dimethyl acetylenedicarboxylate, were not identical. They suggested a mechanism in which the initial step of the photolysis involved formation of the bicyclic diaziridine, 26, which lost carbon dioxide, leading to the formation of a nitrileimine, with subsequent trapping by the dipolarophile.

The irreversibility of the overall reaction, -- photocoloration and thermal bleaching, is further substantiated by the observation that carbon dioxide is produced during the solidstate photolysis and bleaching process. Thus, the appropriateness of the word "photochromic" as applied to N-3-pyridylsydnone comes into serious question. Indeed, the term "photochromism" is generally restricted to reversible photo-induced processes (33). Our results suggest that the photocoloration of 20 is a two-step, essentially nonreversible, photo-initiated reaction, and that the bleaching reaction probably involves the extrusion of carbon dioxide, followed by further reactions which lead to colorless products.

\section{REFERENCES}

1. The research described herein was supported by the Office of Basic Energy Sciences of the Department of Energy. This is Document No. NDRL-1929 from the Notre Dame Radiation Laboratory.

2. Present Address: Eastman Kodak Laboratories, Kodak Research Park, Rochester, NY 14650.

3. H. Kristinsson and G.W. Griffin, Angew. Chem., Int. Ed. Engl. 4, 686 (1965).

4. G.W. Griffin, ibid. 10, 537 (1971) and references therein.

5. H.W. Heine and R.E. Peavy, Tetrahedron Lett. 3213 (1965).

6. R. Huisgen, W. Scheer, G. Szeimies and H. Huber, ibid. 397 (1966).

7. A.M. Trozzolo, Accounts Chem. Res. 1, 329 (1968).

8. A.M. Trozzolo and E. Wasserman, in "Carbenes", R.A. Moss and M. Jones, Eds., WileyInterscience, New York, 1975, Vol. 2, p.185.

9. R.W. Murray and A.M. Trozzolo, in "International Symposium on Microchemical Techniques," N.D. Cheronis, Ed., Interscience, New York, 1962, p.233.

10. A.M. Trozzolo, W.A. Yager, G.W. Griffin, H. Kristinsson and I. Sarkar, J. Am. Chem. Soc. 89, 3356 (1967).

11. T. DoMinh, A.M. Trozzolo and G.W. Griffin, ibid. 92, 1402 (1970).

12. T. DoMinh and A.M. Trozzolo, ibid. 92, 6997 (1970).

13. T. DoMinh and A.M. Trozzolo, ibid. 94,4046 (1972).

14. H. Dietrich, G.W. Griffin and R.C. Petterson, Tetrahedron Lett. 153 (1968).

15. (a) R.S. Becker, J. Kolc, R.O. Bost, H. Dietrich, P. Petrellis and G.W. Griffin, J. Am. Chem. Soc. 90, 3292 (1968); (b) R.S. Becker, R.0. Bost, J. Kolc, N.R. Bertoniere, R.L. Smith and G.W. Griffin, ibid. 92, 1404 (1970).

16. D.R. Arnold and L.A. Karnischky, 1bid. 92, 1404 (1970).

17. R. Huisgen and H. Mader, Angrew. Chem. Internat. Ed. 8, 604 (1969).

18. (a) N.H. Cromwe1l and J.A. Caughlan, J. Am. Chem. Soc. 67, 2235 (1945); (b) N.H. Cromwell and H. Hoeksema, ibid. 71, 708 (1949).

19. H.W. Heine, R.H. Weese, R.A. Cooper and A.J. Durbetaki, J. Org. Chem. 32, 2708 (1967).

20. A. Padwa and L. Hamilton, J. Heterocyc1. Chem. 4, 118 (1967). 
21. A.M. Trozzolo and T. Leslie, unpublished results.

22. R.B. Woodward and R. Hoffmann, Angrew. Chem., Internat. Ed. 8,781 (1969).

23. A. Padwa, S. Clough and E. Glazer, J. Am. Chem. Soc. 92, $177 \overline{8}$ (1970).

24. H.W. Heine and R.P. Hanzel, J. Org. Chem. 34, 171 (1969).

25. A.M. Trozzolo, U.S. Patent 3,964,823 (June 22, 1976); U.S. Patent 3,984,177 (October $5,1976)$.

26. J.M. Tien and I.M. Hunsberger, Chem. Ind. (London), 119 (1955).

27. J.M. Tien and I.M. Hunsberger, J. Am. Chem. Soc., 77, 6604 (1955).

28. T. Mill, A. van Roggen and C.F. Wahlig, J. Chem. Phys., 35, 1139 (1961).

29. N-3-pyridylsydnone was prepared by the procedure described by J.M. Tien and I.M. Hunsberger, J. Am. Chem. Soc., 83, 178 (1961).

30. F.H.C. Stewart, Chem. Revs., 64, 129 (1964).

31. F.I. Metz, W.C. Servoss and F.E. Welsh, J. Phys. Chem. 66, 2246 (1962).

32. C.S. Angadiyavar and M.V. George, J. Org. Chem. 36, 1589 (1971).

33. G.H. Brown, "Photochromism", Wiley-Interscience, New York, 1971. 